\title{
Verismo italiano e subjetividade: o reverso em Luigi Pirandello
}

Andrea Quilian de Vargas*

Rosani Ketzer Umbach ${ }^{\text {** }}$

\section{Resumo}

Inspirado no Naturalismo de Émile Zola, o Verismo italiano foi uma corrente artística que, no final do século XIX e início do XX, caracterizou-se pela crença na possibilidade de a literatura representar objetivamente o real. O intuito deste artigo é refletir sobre como o escritor e dramaturgo siciliano Luigi Pirandello, um descendente do Verismo, abordou a questão da subjetividade em algumas de suas obras. Para alcançar o objetivo proposto, elegemos como objetos de análise $O$ falecido Mattia Pascal, Um, nenhum e cem mil e Cadernos de Serafino Gubbio operador, romances nos quais Pirandello subverte a objetividade proposta pelos veristas, ao mesmo tempo que duvida da possibilidade de o sujeito exercer completamente sua subjetividade, entendida por ele como um complexo mecanismo alterado pela sociedade, pela maquinaria moderna e pelo olhar do Outro.

Palavras-chave: Verismo. Pirandello. Subjetividade.

\section{Verismo italiano e o romance experimental de Zola}

Movimento literário italiano iniciado na segunda metade do século XIX, o Verismo caracterizava-se pela intenção dos escritores em representar objetivamente a realidade social da época, por intermédio de uma narrativa que primava pela rigorosa fidelidade ao real. A origem da linha de pensamento verista está no Naturalismo francês, corrente literária que representava a última evolução do Realismo oitocentesco e que podia ser vista, sob o plano criativo e artístico, como a tradução da filosofia positivista. Da mesma forma como os cientistas po-

\footnotetext{
Mestra em estudos literários pela Universidade Federal de Santa Maria. Doutoranda em estudos literários na mesma instituição. E-mail: andrea.quilian@hotmail. com. Telefone: (55) 81192425.

** Professora titular do Programa de Pós-Graduação em Letras da Universidade Federal de Santa Maria. Coordenadora da linha de pesquisa Literatura, comparatismo e crítica social. E-mail: rosani.umbach@ufsm. br. Telefone: (55) 32208359.
}

Data de submissão: mar. 2016 - Data de aceite: maio 2016 http://dx.doi.org/10.5335/rdes.v12i1.5739 
sitivistas acreditavam que a realidade pudesse ser estudada e compreendida em cada aspecto por intermédio do método experimental, os escritores naturalistas aproximavam os ambientes e as personagens dos romances utilizando um análogo processo de estudo. Se antes o escritor podia intervir nos eventos narrados, atribuindo-lhes juízos de valor, agora adota uma postura imparcial e impessoal. Para os naturalistas, o autor que buscava ser fiel à realidade deveria portar-se como um fotógrafo, sem qualquer espécie de envolvimento subjetivo com a cena, o enredo ou as personagens.

Não obstante o Verismo tenha nascido a partir das ideias do Naturalismo, a descendência não elimina as distinções. Enquanto o segundo era desenvolvido em uma sociedade industrializada e em um contexto predominantemente urbano, o primeiro limitava-se ao âmbito rural, atrasado sob o ponto de vista econômico e cultural. Além disso, ao passo que os naturalistas franceses propagavam certa crença no progresso, a ideologia presente nos textos veristas mostrava-se fortemente pessimista, sendo que quaisquer esforços para melhorar a situação das personagens, predominantemente campesinos, pequenos agricultores ou pescadores, pareciam inúteis.

Os sicilianos Giovanni Verga e Luigi Capuana, juntamente com o napolitano Federico De Roberto, são os maiores expoentes do Verismo. O fundador do movimento é, reconhecidamente, Verga (fiel discípulo do naturalista francês
Émile Zola), com os romances I Malavoglia (1881) e Mastro-don Gesualdo (1889), a coletânea de contos Vita dei campi (1880) e a novela Novelle rusticane (1883), obras que incorporam o uso de expressões idiomáticas do local, típicas da oralidade, com forte influência dialetal. A realidade siciliana, em especial, era o principal objeto de representação dos romances veristas, mas a vertente literária não se esgotou nos limites da Sicília, espraiando-se por toda a Itália.

As bases do Verismo fundado por Verga estão no naturalismo de Émile Zola (1840-1902). Autodenominado romancista experimental moderno, o romance configurar-se-ia, para o escritor francês, como resultado da observação do homem ou, usando outros termos, do estudo científico do homem e de sua alma como mecanismos cognoscíveis. Para alguns críticos, como Hauser (1969), a principal fonte da narrativa naturalista foi a frustrante experiência política da geração de 1848, o fracasso da revolução e a subida ao poder de Luís Napoleão. O malogro dos ideais e das utopias democratas levou alguns escritores mais engajados a protestarem por intermédio de suas penas e tinteiros, contrapondo-se ao idealismo e ao individualismo do Romantismo, com suas fugas da realidade e ideais burgueses de arte pela arte.

Durante a segunda metade do século XIX, a literatura sofreu expressiva influência da corrente cientificista. Teorias do âmbito da química, da biologia, da física e da filosofia estabeleceram relações de 
aberto diálogo com a obra literária. Para Zola, a imaginação havia deixado o romance e, uma vez que ela não era mais a qualidade primordial do escritor, o princípio de criação passava a ser, então, o senso do real. Essa inclinação ao cientificismo pode ser confirmada no ensaio $O$ romance experimental e o experimentalismo no teatro, no qual o escritor indica a equivalência entre Introdução ao estudo da medicina experimental (1865), do médico e fisiologista francês Claude Bernard, e aquilo que deveria ser posto em prática na estruturação do romance.

Em seu ensaio, Zola adverte que bastaria trocar o termo "médico" do texto de Bernard por "romancista" para que se pudesse entender a estrutura do romance experimental. O objetivo de tal método, aplicado à ciência, consistiria em encontrar as relações que prendem um fenômeno qualquer à sua causa próxima, ou, em outras palavras, em determinar as condições necessárias à manifestação desse fenômeno. A ciência experimental não deveria se preocupar com o "porquê" das coisas; ela explicaria o "como" (ZOLA, 1982, p. 27).

Questionando-se sobre a possibilidade de a experimentação ser possível no âmbito da literatura e utilizando-se dos conceitos de Bernard, Zola distingue, inicialmente, dois componentes essenciais: o "observador" e o "experimentador". O primeiro seria aquele que aplica processos de investigação simples ou complexos ao estudo dos fenômenos tal qual eles estão na natureza; o segundo empregaria os mesmos processos de investigação, mas com o intuito de interferir e fazer variar os fenômenos naturais. Para concluir sua hipótese acerca da possibilidade de experimentação no romance, Zola cita um trecho de Introdução ao estudo da medicina experimental:

O observador constata pura e simplesmente os fenômenos que tem diante dos olhos. Ele deve ser o fotógrafo dos fenômenos; sua observação deve representar exatamente a natureza. Ele escuta a natureza e escreve o que ela dita. Mas, uma vez constatado o fato e bem observado o fenômeno, surge a ideia, intervém o raciocínio, e o experimentador aparece para interpretar o fenômeno (ZOLA, 1982, p. 30).

Aplicada ao romance, a teoria de Bernard funcionaria da seguinte maneira:

[...] voltando ao romance, vemos também que o romancista é feito de um observador e de um experimentador. Nele [o romance], o observador apresenta os fatos tal qual os observou, define o ponto de partida, estabelece o terreno sólido no qual as personagens vão andar e os fenômenos se desenvolver. Depois, o experimentador surge e institui a experiência, quer dizer, faz as personagens evoluírem numa história particular, para mostrar que a sucessão dos fatos será tal e qual exige o determinismo dos fenômenos estudados. Trata-se quase sempre de uma experiência "para ver", como designa Claude Bernard. O romancista sai em busca de uma verdade (ZOLA, 1982, p. 31).

Zola resume a construção do romance experimental como um processo que toma os fatos na natureza e depois estuda seus mecanismos, agindo sobre eles pelas modificações das circunstâncias e dos meios. Ao término, assegura Zola (1982, p. 32), há o conhecimento científico do indivíduo em sua ação individual e 
social. Usando outras palavras, o romancista seleciona um determinado fato e $o$ expõe tal como ele se apresenta; em seguida, submete os elementos envolvidos na configuração desse fato a alterações e, por fim, analisa as mudanças de comportamentos que advém dessa intervenção para encontrar respostas: como age o homem nesta ou naquela circunstância?

O romance experimental, dessa forma, configura-se uma experiência verdadeira que o romancista faz com o homem, apoiando-se na observação. Nessa espécie de "romance de laboratório", o homem metafísico não encontra mais espaço e qualquer subjetividade é eliminada do processo criativo. No terreno do romance experimental, é o homem fisiológico que interessa, aquele que pode ser cientificamente estudado. A postura experimental e quase tecnicista dos naturalistas rendeu-lhes algumas críticas incisivas, entre elas a de serem somente "fotógrafos da realidade". A essa análise, Zola responde:

Por mais que declaremos que admitimos o temperamento e a expressão pessoal, continuam a nos responder com argumentos imbecis sobre a impossibilidade de ser estritamente verdadeiro, sobre a necessidade de arranjar os fatos para constituir uma obra de arte qualquer. Pois bem, com a aplicação do método experimental ao romance, cessam todas as querelas. A ideia da experiência traz em si a ideia de modificação. Partimos realmente dos fatos verdadeiros, que constituem nossa base indestrutível; mas, para mostrar o mecanismo dos fatos, temos que produzir e dirigir os fenômenos. Essa é nossa parte de invenção e de gênio na obra (1982, p. 34).
O subjetivismo ou a genialidade do escritor está na escolha das circunstâncias que serão alteradas no jogo narrativo e nas diferentes situações às quais serão expostas as personagens. O romancista, assim, é tomado por sua inteligência de pensador e seu gênio criador, que o levarão a ver, compreender e inventar. Todavia, em seu texto, Zola jamais abandona a ideia de que se pode encontrar uma verdade, um conhecimento absoluto do homem e dos mecanismos que regem as suas paixões por intermédio da observação de um fato e suas consequências. $\mathrm{O}$ escritor, partindo de uma dúvida inicial acerca de um caso qualquer, só deixa de duvidar quando o funcionamento da vontade humana é desmontado e montado novamente. Em síntese, os romancistas naturalistas observam e experimentam, sendo que todo seu trabalho nasce da dúvida em que se colocam diante das verdades mal conhecidas, dos fenômenos inexplicados, até que uma ideia experimental desperte bruscamente seu gênio e os leve a instituir uma experiência para analisar os fatos e dominá-los.

$O$ romance naturalista seria, portanto, o resultado da observação e das experimentações feitas sobre o homem, com o intuito de dissecá-lo. Não é por acaso que, nesse mesmo contexto, surge a psicologia, com o intuito de desvendar os mistérios da alma humana. Partindo da peremptória afirmação de Zola, perguntamo-nos: será possível dominar os fatos? Será factível desvendar os segredos da consciência humana? Se- 
rão as paixões e os apetites do homem passíveis de uma análise laboratorial e científica? É previsível o comportamento do homem?

\section{O contraponto em Notas do subsolo}

\section{Contemporaneamente a Zola e Ver-} ga, um dos maiores escritores russos, Fiódor Dostoiévski, escreveu uma obra que seria considerada decisiva para compreender o romance moderno do final do século XIX e início do XX. Em Notas do subsolo (1864), a ideia defendida por Zola é questionada, tendo em vista que o desejo de conhecer cientificamente a alma humana é entendido como um delírio, pois o homem é um mistério, e a realidade é uma utopia. Vejamos um trecho do texto de Dostoiévski:

[...] se algum dia encontrarem mesmo a fórmula de todos os nossos desejos e caprichos, ou seja, aquilo de que eles dependem, as leis segundo as quais eles se produzem, como precisamente se espalham, que objetivos eles buscam num caso ou noutro, etc., ou seja, se encontrarem uma verdadeira fórmula matemática - aí talvez o homem imediatamente deixe de ter vontade e, digo mais, ele seguramente fará isso. Quem vai querer ter vontade de acordo com uma tabela? E ainda: no mesmo instante o homem se transformará num pedal de órgão ou em algo no gênero; porque o que é esse homem sem desejos, sem vontade, sem seu próprio querer, senão um pedal de órgão? Que acham disso? Examinemos as probabilidades: pode isso acontecer ou não? [...] Porque se, por exemplo, um dia me provarem com cálculos que se eu fiz um gesto obsceno com o dedo para alguém isso se deu precisamente porque não poderia deixar de fazê-lo, e porque era exatamente aquele dedo que eu deveria mostrar, então o que restará de livre em mim, especialmente se sou uma pessoa instruída e com um curso completo de ciência em algum lugar? Pois nesse caso eu vou poder calcular antecipadamente toda a minha vida futura por um período de trinta anos; em síntese, se isso for implantado, não nos restará nada a fazer; de todo modo, teremos de aceitar. E, de maneira geral, devemos repetir para nós mesmos sem descanso que, forçosamente, num determinado minuto e em certas condições, a natureza não pede a nossa opinião; que é necessário aceitá-la tal como ela é, e não como nós a fantasiamos, e se, de fato, almejamos chegar a uma tabela e a um calendário e a... bem, nem que seja a um tubo de ensaio, então, que se há de fazer, é preciso admitir também o tubo de ensaio! [...] Vejamos senhores: a razão é uma coisa boa, sem dúvida, mas razão é apenas razão e satisfaz apenas a capacidade racional do homem; já a vontade, esta é a manifestação da vida como um todo, ou melhor, de toda a vida humana, aí incluindo-se a razão e todas as formas de se coçar. E, mesmo que a nossa vida pareça às vezes bem ruinzinha do ponto de vista acima, ela é vida, apesar de tudo, e não apenas a extração de uma raiz quadrada (2008, p. 15-16, grifo do autor).

Para Dostoiévski, a complexa tarefa de estudar cientificamente as paixões e vontades do ser humano seria o mesmo que reduzi-lo a um utensílio, uma coisa qualquer, ou ao resultado de uma raiz quadrada. O propósito naturalista é definitivamente impossível, segundo o escritor russo, pelo simples fato de que o homem é um ser dotado de vontade, que não obedece a fórmulas matemáticas ou a leis da ciência. Nem o homem nem a realidade podem ser vistos sob o olhar da ciência, exclusivamente. Tampouco uma fotografia é capaz de mostrar a realidade em si, pois ela nada mais é do que a 
relação do fotógrafo com aquilo que ele vê através da lente: é ele quem escolhe o ângulo, a inclinação, a perspectiva, o enfoque que dará a um determinado espaço que será por ele delimitado. Em outras palavras, é impossível representar a realidade "assim como ela é". O "princípio da incerteza"1 de Heisenberg (1980), para exemplificar, demonstra que nem mesmo a ciência é exata: a presença de um observador altera aquilo que é observado. Se levado em conta o fato de que o ser humano interage com o mundo vendo-o e interpretando-o por meio dos filtros de sua subjetividade, o sonho positivista pode ser considerado um tanto delirante.

Ao mesmo tempo em que o embate titânico entre Zola e Dostoiévski acontecia, em outra parte da Europa, distante da efervescência cultural francesa, o italiano Giovanni Verga, discípulo confesso de Zola e do naturalismo, lançava $I$ Malavoglia (1881) e Mastro-don Gesualdo (1889), obras fundadoras do Verismo italiano no final do século XIX. Verga aplicava no contexto italiano, ou siciliano, mais especificamente, a proposta de Zola de representar objetivamente o real. Leiamos o prefácio de I Malavoglia:

Este relato é o estudo sincero e desapaixonado de como, provavelmente, devem nascer e se desenvolver nas condições mais humildes as primeiras inquietações pelo bem-estar; e que perturbação deve trazer a uma pequena família, que viveu até então relativamente feliz, a vaga cobiça do desconhecido, o perceber que não se está bem, ou que se poderia estar melhor. O movente da atividade humana que produz a cheia do progresso é tomado aqui em suas nascentes, nas proporções mais modestas e materiais. $\mathrm{O}$ mecanismo das paixões que a determinam naquelas baixas esferas é o menos complicado e poderá, portanto, ser observado com maior precisão. Basta seu desenho simples. À medida que essa procura pelo melhor, que atormenta o homem, cresce e se dilata, tende também a elevar-se e segue o seu movimento ascendente nas classes sociais. Em Os Malavoglia trata-se tão somente da luta pelas necessidades materiais (VERGA, 2010, p. 7).

Submersas na vaidade e no desejo de “estar melhor", as personagens vão se envolvendo em complicados mecanismos, sendo que todas elas, da mais humilde a mais abastada,

[...] são [a]os mesmos[as] vencidos[as] que a correnteza depositou na margem, depois de tê-los arrastado e afogado, cada um com os estigmas do seu pecado (VERGA, 2010, p. 9).

Observar essas personagens de fora do campo da luta é a proposta de Verga em Os Malavoglia (1881). A história da família se desenvolve em um período em que, além da agitação da nova realidade moderna do século XIX, conflitos internos abalam a Itália, sendo que até mesmo na remota Trezza, uma vila de pescadores, o progresso ecoa e as primeiras inquietações pelo bem-estar estão presentes. Os Malavoglia são uma família de pescadores há muitas gerações, cuja composição é resumida nas páginas iniciais do primeiro capítulo do romance: "E a família do patrão 'Ntoni estava realmente disposta como os dedos da mão" (VERGA, 2010, p. 14), cada um com suas atribuições bem definidas. 
A questão levantada no romance não é transcendental, como a justiça, o infinito, a verdade ou a felicidade, mas o bem-estar. Usando outros termos, a questão não é existencial, mas está intrinsecamente ligada ao melhoramento da condição social, ao "como" estar melhor em sociedade. A proposta narrativa de Verga é simples: a desafortunada família de pescadores tenta enriquecer vendendo tremoços. O ideal positivista e naturalista estaria perfeitamente representado no romance, bastando analisar como iriam agir, nas personagens, os dispositivos das paixões e apetites oriundos dos experimentos escolhidos pelo escritor.

Entretanto, ao lermos I Malavoglia, damo-nos conta de que o studio spassionato não ocorre como um experimento científico. Pode-se dizer que o escritor é um narrador eclipsado que gira com uma câmera nas costas, mas é ele quem escolhe o ângulo, a perspectiva, o que importa revelar ou não sobre cada fato narrado. Da mesma forma, cabe ao leitor entender aquilo que é narrado, incluindo na sua interpretação individual aqueles elementos que Verga julgava conseguir excluir, como a identificação e a empatia do receptor com aquelas tristes personagens. No prefácio do romance, Verga declara que o leitor não tem o direito de julgar aquilo que lê. Todavia, o escritor desconsidera peremptoriamente em sua assertiva o princípio da criticidade que subjaz à criação e à recepção literárias.
Talvez o fundador do Verismo não tenha previsto o valor que seu romance alcançaria posteriormente como testemunho das desgraças do homem siciliano, e não somente como documento oriundo da observação e experimentação sobre esse homem. Alfredo Bosi, em Céu, inferno: ensaios de crítica literária e ideológica, assevera que Verga retratou, em sua obra, a realidade dos:

servos da gleba ou dos pescadores da sua Sicília ainda semi-feudal há duas ou três gerações. [...] um mondo chiuso, uma ilha no espaço e no tempo. Verga contou a vida daqueles homens. Sem comentários nem retórica, com uma sobriedade viril que deu à dimensão do "documento regional", seu objetivo consciente, outro valor: o de testemunho trágico da condição humana (BOSI, 2003, p. 287).

Ana Paula Freitas de Andrade afirma, em sua tese de doutorado intitulada Os Malavoglia: o narrador e sua criação (2006), que a primeira edição do romance não alcançou o sucesso esperado por Verga, após exaustivos cinco anos de trabalho. Influenciado pelo declarado anseio de impessoalidade pretendido por Verga, seu amigo Luigi Capuana afirmou em uma resenha publicada no primeiro periódico italiano de difusão nacional, o Fanfulla della Domenica, que Os Malavoglia era um romance de vanguarda, que tinha alcançado o ideal da impessoalidade narrativa como nenhum outro romance moderno.

Somente depois da virada do século XIX é que a obra-prima de Verga foi reconhecida. Uma legião de jovens escritores da década seguinte adotou o autor 
como mestre de uma literatura nova, engajada na realidade social e moral da Itália moderna, como assevera Andrade (2006). Pode-se dizer que o mestre do Verismo ultrapassou as barreiras do Naturalismo, adotando uma perspectiva diferenciada sobre narrar os fatos nos moldes de Zola, que incluía, mesmo que de forma inconsciente, a subjetividade interpretativa. Tal perspectiva seria também evidenciada, mais tarde, na obra do escritor e dramaturgo siciliano Luigi Pirandello, cuja obra teve início nesse mesmo contexto artístico.

\section{Luigi Pirandello e a subversão ao Verismo: referencialidade versus subjetividade}

Pirandello ora se aproximava ora se afastava dos moldes veristas. A aproximação decorria de seu interesse em explorar aspectos psicológicos nas personagens; o afastamento adveio da insatisfação de Pirandello ao ler seus primeiros contos e não ver neles representado o homem moderno, fraturado e incompleto. Visualizava, ao contrário, a multiplicação e a repetição de enredos, situações, personagens, ambientes e estados de espírito, em textos contaminados pela referencialidade verista. Segundo João Carlos Felix de Lima, em sua tese de doutorado intitulada Cultura, imaginação literária e resistência em Alfredo Bosi:
[...] quando estudante universitário, em Bonn, Pirandello já vinha elaborando experimentos de uma prosa mais límpida, mais avessa à retórica tradicional antirettorica . Difícil dizer o que o acompanhava nesta época, mas pode-se esboçar que as imagens expostas indicavam uma medida de homem contemplado, de homem existencialmente vívido, e sua recusa à representação desse homem nos moldes veristas [...] seria menos encontrável nos contos (2012, p. 106).

Para ultrapassar a referencialidade da narrativa verista, Pirandello passa a observar o homem como sujeito individualizado, apartado de uma perspectiva totalizante ou como produto de alguma espécie de segmento econômico ou nacional, comum nos romances realistas. Falar em romance, como afirma Walter Benjamin, é tratar do isolamento do indivíduo e de sua incapacidade de narrar ou dar conselhos:

O primeiro indício da evolução que vai culminar na morte da narrativa é o surgimento do romance no início do período moderno. O que separa o romance da narrativa (e da epopeia no sentido estrito) é que ele está essencialmente vinculado ao livro. [...] O romancista segrega-se. A origem do romance é o indivíduo isolado, que não pode mais falar exemplarmente sobre suas preocupações mais importantes e que não recebe conselhos nem sabe dá-los. Escrever um romance significa, na descrição de uma vida humana, levar o incomensurável a seus últimos limites. $\mathrm{Na}$ riqueza dessa vida e na descrição dessa riqueza, o romance anuncia a profunda perplexidade de quem a vive (1987, p. 201).

Segregação e perplexidade são as palavras utilizadas pelo pensador alemão para caracterizar, grosso modo, o romance moderno. Com base nessa hipótese, adentramos o universo de alguns textos 
de Luigi Pirandello, começando por Il fu Mattia Pascal, primeiro romance e um divisor de águas na obra do siciliano. Quando a história do bibliotecário Mattia Pascal foi contada, em 1906, Pirandello havia iniciado sua carreira de romancista com L'esclusa (1901) e Il turno (1902), duas propostas de narrativas com ambientação siciliana que não pareciam representar um presságio do que viria a seguir, o giro narrativo pirandelliano. Todavia, L'esclusa já apresentava certo distanciamento do cânone naturalista: na história da mulher que é acusada de adultério e expulsa de casa, para depois ser novamente reinserida à família, é um dos temas muito caros a Pirandello, como o conflito entre as aspirações individuais e as convenções sociais e a difícil simultaneidade entre verdade e mentira. Pirandello inicia sua carreira de romancista, incentivado por Luigi Capuana, como seguidor do Naturalismo, rebatizado como Verismo na Itália, mas uma releitura de L'esclusa, anos depois, o faz refletir mais claramente sobre a obra, levando-o a rever sua posição: seu romance "mais verista" antecipava a poética sucessiva, o romance humorístico.

$\mathrm{Na}$ reedição de 1908 de L'esclusa, segundo Claudia Sebastiana Nobili, em Pirandello: guida a Il fu Mattia Pascal (2004, p. 16), Pirandello escreve uma dedicatória a Capuana entendida como um adeus ao Verismo. O aparente tributo ao grande teórico verista demarcou a tomada de distância efetuada por Pirandello. Da mesma forma que L'esclusa assinalou o distanciamento entre Pirandello e Capuana, Il fu Mattia Pascal demarcou o afastamento de Verga. Por decorrência de um encontro fortuito entre os dois escritores na redação da Nuova antologia, a revista que primeiramente publicara o romance em capítulos, Verga recebe o livro enfim editado e é o primeiro a ler Il fu Mattia Pascal. Algum tempo depois, Pirandello recebe uma carta de um Verga gentil, que declara sentir-se ultrapassado e que se congratula pelo surgimento de um novo romancista, cuja arte renovadora se mostrava no romance que contava os malogros de um perdido bibliotecário, Mattia Pascal.

Pirandello, um sincero admirador de Verga, via nele agora um mestre do qual deveria se emancipar e seguir caminhos distintos, para não mais cair na armadilha de repetir com vozes menores o que 0 mestre havia dito com força maior. Assim como Verga descobriu a vida miúda da plebe siciliana, com seus conflitos éticos e econômicos, Pirandello lança seu olhar para o sujeito em crise com a própria identidade e cindido com a realidade. Sobre isso, assim escreve Nobili:

Superato Il verismo e la fidúcia ancora positivistica nella possibilità di descrivere Il mondo “così com'è”, Pirandello si cala nella "prospettiva copernicana dell'intellettuale che há scoperto il dubbio permanente nella condizione storica delle sue criature" (de Castris, in Laureatta, 2001, p. 23): è Mattia Pascal l'eroe di quel dubbio, Il personaggio incapace di scendere a patti com La realtà. Tentano ancora dal realismo in anni successivi, soprattutto quando realizerà le sue opere teatrali di ambientazione siciliana (Loilà, La giara, La patente), Pirandello 
tuttavia lo archivia com Il Mattia Pascal, come Verga comprende alla lettura del romanzo. Verga e Capuana restano i maestri ammirati e ricordati com deferenza, ma nel 1904 Pirandello comincia già a liberarsi di quei padri amati eppure scomodi, ai quali deve i suoi primi passi e daí quali avverte il bisogno di allontanarsi (2004, p. 17).

Anos depois, por ocasião de uma conferência que celebrava os cinquenta anos de I Maravoglia, Pirandello reflete sobre os ensinamentos de Verga recordando que, para alguns críticos, seu mestre limitava-se a falar sobre as coisas e o mundo "così com'è". Para Pirandello, entretanto, a afirmação não podia ser exata, pois não há como depreender o mundo "così com'è", a realidade não é objetiva, mas se configura de acordo com a forma como nós a interpretamos. Então, para compreender a obra de Verga,

[...] é necessário ver quais sentimentos se encontram interpostos entre ele e 'sua realidade'. Para Pirandello, a paixão e o tormento do mestre o levaram a criar seu estilo próprio (NOBILI, 2004, p. 18, tradução nossa).

A mesma regra, o olhar em perspectiva, passa a ser uma das características mais marcantes do siciliano. Mattia Pascal, e com ele Vitangelo Moscarda e Serafino Gubbio, são personagens que contribuíram definitivamente para colocar Pirandello entre os escritores que, assim como Dostoiévski, desacreditaram na mentira oitocentista de uma única realidade a descrever, sendo Mattia Pascal o herói dessa descrença.

Mattia é a primeira personagem romanesca pirandelliana atormentada pelo demônio da reflexão crítica: seu contínuo interrogar-se sobre as próprias ações e sua relação com os outros, assim como sobre o sentido da vida e dos papéis que ele mesmo deveria representar (como bibliotecário, como Adriano Meis, como o falecido Mattia Pascal), são indícios do que aconteceria depois em $\mathrm{Sei}$ personaggi in cerca d'autore, em Enrico $I V$, em Uno, nessuno e centomila e com todas as demais personagens que se dão conta de uma dramática realidade: retiradas as máscaras, tornam-se nuas, vazias diante de si mesmas.

Mattia Pascal é o sonhador filho de uma viúva que perdera toda a fortuna pelas mãos de um desonesto administrador, Batta Malagna. Seu único amigo é o tímido Pomino, apaixonado pela bela Romilda, filha da megera viúva Pescatore e sobrinha de Malagna. Pomino, sem coragem de se declarar a Romilda, pede a Mattia que se aproxime da jovem para sondá-la. Todavia, Mattia e Romilda se apaixonam e ela engravida. Malagna, ávido por um herdeiro e certo da infertilidade de sua jovem esposa, decide assumir o filho de Romilda e Mattia como seu, e abandona Oliva. Essa, desesperada, procura a família de Mattia para chorar sua desgraça. Vendo nesse fato a possibilidade de vingar-se por Oliva, Mattia conta a verdade sobre os planos do então ex-marido para Oliva e a engravida, obrigando Malagna a reconhecer o filho que não é seu e voltar para casa. O jogo do "astuto" bibliotecário, no entanto, dá errado: Malagna obriga que ambos se casem, Mattia e Romilda, para 
limpar a honra da sobrinha. É dessa forma que a desgraçada vida do bibliotecário, assim como a dos outros moradores do lugarejo, se configura.

Claro está, após essa breve introdução a Il fu Mattia Pascal, que o pessimismo moderno invade cada uma dessas personagens. Mesmo que relutem ou tentem resistir, todos são perdedores, em maior ou menor grau: a mãe de Mattia perde toda sua fortuna; o pobre Pomino ama Romilda, mas com ela não se casa (pelo menos no início da narrativa), Oliva tem um filho com Mattia, que não a ama, Mattia é obrigado a casar com Romilda e viver com a sogra que odeia e Malagna reconhece um filho que não é seu. Em outros termos, não existe possibilidade de felicidade para essas criaturas, todas à deriva de um destino incerto e cruel, onde o Outro é sempre uma ameaça. Essa condição de perdedores na vida é tão acentuada em Pirandello que é aceita como normal, sendo que cada estrutura particular de derrota torna-se geral, como se isso fosse a vida propriamente dita: o ser humano está aqui, neste mundo, para perder.

Segundo Raymond Williams:

O mundo dramático [de Pirandello] é um mundo de culpa e ilusão: a culpa entrelaçando-se e assumindo uma feição complexa em uma série de falsas relações pessoais: a ilusão elaborada e persistente, como um meio de evitar a culpa ou de viver com ela. $\mathrm{E}$, no entanto, este não é apenas um mundo peculiar: ele é deliberadamente generalizado. Relações sinceras e verdadeiras tornam-se impossíveis, e a única defesa contra o sofrimento, a única fonte de inocência, é a fantasia (2002, p. 192).
Se relacionarmos a afirmação de Williams à resolução de Mattia Pascal em escrever um livro para contar a sua triste história (como ele declara no início do romance), é possível depreender que a única saída para o bibliotecário está, realmente, na ficcionalização da própria vida. $\mathrm{O}$ que fazer com uma existência tão malograda? Talvez alguém que a leia, no futuro, encontre alguma real significação para tanta desgraça. Da mesma forma, aí também está a saída de Pirandello: um homem que manteve um casamento inexistente, dada a condição de saúde da esposa (internada em um sanatório); e que amou profundamente a jovem atriz Marta Abba, na maturidade, sem poder viver essa relação. Assim como Mattia Pascal, Pirandello ficcionalizou a própria vida na tentativa de nela encontrar algum sentido.

Vejamos o que acontece a seguir na vida de Mattia Pascal: em uma estação de trem, vê seu nome na página necrológica do jornal local. Após ter passado alguns dias jogando em Monte Carlo, Mattia fora considerado desaparecido e, segundo o jornal, estava morto. $\mathrm{O}$ defunto havia sido encontrado nas suas terras e reconhecido pela esposa e a sogra, com quem Mattia havia se desentendido antes da partida. Com oitenta e duas mil liras no bolso, uma quantia de certo vulto na época, o desatento protagonista leu sobre seu suicídio na primeira página do jornal local. Inicialmente, a vontade de Mattia foi desfazer aquela mentira. Entretanto, refletindo melhor, essa era a ocasião 
para recomeçar a vida. A partir de então, Mattia Pascal, o falecido, mergulhou na construção de uma nova identidade, batizada com o nome de Adriano Meis.

Giacomo Debenedetti, conhecido crítico literário italiano, ao fazer um estudo sobre as personagens de Svevo, formulou uma interessante análise:

[...] diseredato do ogni felice istinto del vivere e privo di abbandono, a paragone col tipo antitético dell'ariano; inoltre uma instabile molteplicità del fondo moral e lo renderebbe plástico, disponibile e deformabile a tutti gli urti; femminilmente passivo (1990, p. 58).

A assertiva de Debenedetti, que resume a personagem como "disponível, deformável, plástica”, pode ser perfeitamente aplicada a Mattia: o protagonista de Il fu Mattia Pascal é disponível porque não encontrou uma finalidade na vida e age, quase sempre, à mercê do destino e influenciado pelos outros: corteja Romilda para aproximá-la de Pomino, e engravida Oliva para que ela, paradoxalmente, possa retomar seu casamento. Tenta mudar de vida, de cidade, de nome, corrige um olho torto, mas continua "deformável", um ser flutuante no mundo, onde jamais encontra a si mesmo. Nem mesmo quando tem em suas mãos o poder de mudar o próprio destino, Mattia vence. Ao contrário, esmorece e perde para ele mesmo, ou para a sua sombra, Adriano Meis.

Ao saber que estava oficialmente morto e decidir embarcar nessa mentira, sua disponibilidade torna-se perfeita. É nesse ponto que, no romance, poderia haver uma reviravolta, o pacato bibliotecário poderia começar a reagir diante das circunstâncias que a vida, até aquele momento, lhe apresentara. Todavia, ele opta pela comodidade de se reinventar, em vez de tentar descobrir quem ele era. Mas como criar uma personalidade fictícia, se nem mesmo a verdadeira era conhecida? Mattia Pascal estava condenado a viver em eterna disponibilidade, a ser um eterno adolescente que jamais reconheceria a si mesmo.

[...] qui starebbe il limite, secondo Debenedetti, del romanzo di Pirandello, e l'incapacità dell'autore di varcare la soglia del novecento mettendo la coscienza del personaggio al centro del proprio interesse (NOBILI, 2004, p. 45).

Mattia não fez outra coisa além de repetir atos de transgressão impotentes que não o levaram a lugar algum. Primeiramente, é obrigado por Malagna a casar, depois, em sua segunda vida como Adriano Meis, dobrar-se-á à vontade de Papiano, o rival pelo amor da doce Adriana. A sonhada liberdade, longe da esposa e da sogra, não passava de um devaneio. Livres estavam elas, conclui o pobre Mattia, enquanto ele tinha que carregar o peso de fazer:

[...] papel de morto, com a ilusão de poder tornar-se outro homem. [...] Outro homem, sim, mas com a condição de não fazer nada! E que espécie de homem, então? Uma sombra de homem! E que vida? Enquanto me contentara com ficar trancado em mim e ver os outros viverem, sim, pudera, bem ou mal, salvar a ilusão de que estava vivendo outra vida; mas agora que me beirava desta, até colher um beijo em dois lábios queridos, era obrigado a retirar-me dela, horrorizado, como se houvesse beijado Adriana com os lábios de um defunto que não podia reviver para ela! (PIRANDELLO, 1981, p. 236). 
A verdade estarrecedora que assombrou Mattia Pascal foi descobrir que, mesmo quando ele decide escolher e tem a oportunidade de viver sob seu próprio arbítrio, um fato qualquer despeja sobre ele uma cruel realidade: a impotência diante da vida e a indissolúvel relação entre o Eu e o Outro. Adriano Meis teve parte de seu dinheiro roubado. Como dar queixa? De que forma reagir? Como lutar para reaver o que era seu se nada em sua atual vida era verdade? Qual crime seria considerado de maior relevância? O do ladrão ou o seu? Mais uma vez, o destino lhe dá uma rasteira. Precisava, novamente, trancar-se em si mesmo, por mais difícil que fosse essa convivência. Desconfortável como Mattia Pascal, todavia incomodado, na mesma proporção, como Adriano Meis, decide desistir e mata sua criação forjando um suicídio, retornando para sua antiga morada e para o inevitável encontro com aqueles que o consideravam morto.

Wladimir Krysinski (1988, p. 137) é bastante pontual ao afirmar que Pirandello problematiza a subjetividade como uma célula autocontemplativa que, ao mesmo tempo, se encontra desconfortável frente à coletividade. Toda sua obra parece proceder de uma crítica ao social, entendido como um emaranhado de instituições, eventos e linguagens em que o Eu aprisionado se debate, sendo que a subjetividade desse sujeito, dessa forma, adquire um caráter quase patético. Segundo Pirandello, não há possibilidade de o indivíduo exercer sua individualidade por completo, pois, como podemos ver em $O$ falecido Mattia Pascal, foi absorvido pelas relações sociais de forma devastadora. A desmistificação da autonomia do Eu, como aponta Krysinski (1988, p. 139), é tema constante em Pirandello, que representa o homem moderno como um ser contraditório, fragmentado e compulsoriamente submetido ao olhar do Outro.

Vitangelo Moscarda, o protagonista do romance $U m$, nenhum e cem mil, é um exemplo perfeito. Ao ouvir da esposa que seu nariz era torto, que suas orelhas não eram simétricas e que suas sobrancelhas pareciam dois acentos circunflexos, Moscarda submerge em um complexo processo de tomada de consciência da fragilidade do sujeito frente ao olhar do Outro. Ele descobre que somos tão somente aquilo que parecemos, de modo completamente relativista. Aloja-se, então, na mente da personagem, uma inquietante dúvida: quem era ele, na verdade? Para si próprio, ele era um? Nenhum? Cem mil imagens e construções. Submerso em um mundo que em algo se assemelha ao do "homem subterrâneo" de Dostoiévski, Moscarda reflete sobre a vida e sua relação com os outros:

Nunca mais me olhei num espelho e nem me passa pela cabeça querer saber o que aconteceu com meu rosto e a minha aparência. Aquela que eu apresentava diante dos outros deve ter mudado muito, e de modo bastante cômico, a julgar pelo espanto e pelas risadas com que fui acolhido. [...] Nenhuma lembrança resta, hoje, do nome de ontem - ou do nome de hoje, amanhã. Se 
o nome é a coisa, se um nome é, em nós, o conceito de cada coisa situada fora de nós, e se, sem nome, não há conceito, ficando em nós a coisa como cega, indistinta e indefinida, então cada um grave aquele nome que tive entre os homens, entalhando-o como um epitáfio sobre a fronte daquela imagem com que lhes apareci, deixando-a em paz e relegando-a ao esquecimento. Um nome não é mais do que isso: um epitáfio. Convém aos mortos, aos que concluíram. Eu estou vivo e sem conclusão (PIRANDELLO, 2010, p. 206-207).

Um, nenhum e cem mil é uma narrativa que tematiza não somente o homem fragmentado, dividido em um caleidoscópio de imagens, mas também a busca pelas origens da subjetividade de Moscarda, que rompe definitivamente com a realidade objetiva. A solidão, por fim, torna-se a companhia mais adequada ao pobre banqueiro eclipsado, no final da vida, por sua mais lúcida loucura: a renúncia a qualquer disfarce ou máscara social que integra o indivíduo à sociedade. Para a esposa, Vitangelo Moscarda era Gengê, o pacato e quase patético marido; para os amigos, era o acomodado Vitangelo; para os habitantes da pequena cidade, era conhecido como o "usurário" banqueiro, herdeiro do pai. Dessa forma, o protagonista se encontra submetido a várias realidades, sendo que nenhuma era reconhecida por ele mesmo. Segundo Raymond Williams, a tragédia exposta em algumas obras de Pirandello é justamente a existência da alteridade:
A falsa sociedade é vista, por um momento, como um fato em si mesmo. Mas não há saída no universo de Pirandello, porque a pressão é constante: a pressão da realidade dos outros, com os seus próprios modos de pensar e agir, a sua própria e inevitável conversão dos seus significados nos significados deles, e só se pode transpor um tal mundo por meio do entrelaçamento de ilusões. $\mathrm{O}$ dia que jaz a nossa frente nunca pertence realmente a nós, mas a eles [...] (WILLIAMS, 2002, p. 199).

Em Advertência sobre os escrúpulos da fantasia, Pirandello afronta essa alteridade, metaforicamente denominada "zoólogo", que busca sempre as generalizações, que não reconhece o diferente e que, dessa forma, tenta aprisionar o homem dentro de seus padrões e conceitos. Ao homem, segundo Pirandello, não pode acontecer nenhuma desgraça, como perder uma perna ou um olho:

O homem do zoólogo tem sempre duas pernas, nenhuma delas de pau; tem sempre dois olhos, nenhum deles de vidro. E é impossível contradizer o zoólogo. Porque o zoólogo, se lhe apresentarmos um fulano com uma perna de pau ou com um olho de vidro, responderá que não o conhece, porque aquele não é o homem, mas um homem. É verdade, porém, que todos nós, por nossa vez, podemos responder ao zoólogo que o homem que ele conhece não existe e que [...] existem os homens, nenhum dos quais é igual ao outro, e que podem, inclusive, por uma desgraça, ter uma perna de pau ou um olho de vidro (PIRANDELLO, 1972, p. 283, grifo do autor).

À fôrma do zoólogo, que enquadra, caracteriza, classifica e não admite aberrações ou nada que destoe do compasso orquestrado pelas mãos divinas ou pelas leis da biologia ou da física, Pirandello 
responde com as absurdidades de suas personagens e seus enredos. Vitangelo Moscarda, em Um, nenhum e cem mil, não deixa dúvidas sobre a inexequibilidade de qualquer projeto que pretenda "formatar" ou "racionalizar" completamente o comportamento do ser humano:

Porém me esforçarei para lhes dar, não duvidem, aquela realidade que vocês creem possuir, ou seja, tentarei criar em mim aquela realidade que vocês querem. Isso não é possível, como muito bem o sabemos, já que, fora os esforços que eu faça para representar-me a seu modo, será sempre "um modo seu" apenas para mim, não "um modo seu" para vocês e para os outros. Mas me desculpem: se para vocês eu não tenho outra realidade além daquela que vocês me dão, e estou pronto a reconhecer que ela não é menos verdadeira do que aquela que eu poderia me dar, que esta é, aliás, a única verdadeira a seus olhos (e Deus sabe qual é essa realidade que vocês me dão), talvez agora vocês se lamentem daquela que eu lhes darei, mesmo com toda a boa vontade de representá-los ao seu modo, na medida das minhas possibilidades. Não presumo que vocês sejam como eu os represento. Já afirmei que vocês não são nem sequer aquele um que se representam a si mesmos, mas muitos ao mesmo tempo, segundo todas as suas possibilidades de ser e os casos e as relações e as circunstâncias. E então, qual o meu erro? Vocês é que se equivocam em relação a mim, achando que eu não tenho ou não posso ter outra realidade afora esta que vocês me dão, a qual é apenas sua, acreditem; uma ideia sua, aquela que fizeram para mim, uma possibilidade de ser tal como vocês a percebem, como lhes parece, como reconhecem possível em vocês - já que, sobre aquilo que eu possa ser para mim, não só vocês não podem saber nada, mas tampouco eu mesmo (PIRANDELLO, 2010, p. 94).

Se pensarmos a obra de Pirandello tendo em mente o contexto caótico da modernidade do final do século XIX e primórdios do século XX, podemos afirmar que não é possível determinar uma gramática ou um sistema discursivo da modernidade, mas se pode encontrar certa lógica no teatro e na literatura modernos com base nas palavras de Baudelaire: "A modernidade é o transitório, o efêmero, o contingente, é a metade da arte, sendo a outra metade o eterno e o imutável" (1988, p. 174). Nesse sentido, a forma pirandelliana de captar o transitório consiste na insistência em abordar o descentramento do Eu e da obra, o que ocorre mediante a desarmonia, os finais inconclusivos e o mal estar presentes em muitos de seus textos. Dessa forma, nenhuma relação é duradoura ou permanente em Pirandello, tudo é transitório, temporário, fugaz, assim como a vida moderna. Vida que, para o siciliano, pode ser muito mais inverossímil e sem sentido do que a arte.

É justamente a busca do sentido da vida que move Pirandello em uma época em que, segundo Weber, os homens não passam de

[...] especialistas sem espírito, sensualistas sem coração; e essa nulidade caiu na armadilha de julgar que atingiu um nível de desenvolvimento jamais sonhado antes pela espécie humana (WEBER, 1904 apud BERMAN, 1986, p. 26).

Wladimir Krysinski, em Il paradigma inquieto: Pirandello e lo spazio comparativo della modernità $(1988$, p. 33$)$, assinala que a inquietude de Pirandello insere-se no quadro de um gosto artístico que, no início do século XX, era comum 
a alguns grandes criadores, como Joyce, H. James. V. Woolf, Musil, entre outros, que sinalizavam para a morte do homem liberal.

Segundo Krysinski, o escritor austríaco Robert Musil foi, sem dúvida, o criador e o analista mais sutil e o que melhor articulou esse processo, especialmente em Uomo senza qualità. Nesse romance, Musil diagnostica uma misteriosa doença da época: a vida europeia não coincidia com a ideologia europeia. $\mathrm{O}$ professor Walter Moser, da Universidade de Otawa, é citado por Krysinski como o mais pontual examinador da questão da morte do homem liberal na obra de Musil. De acordo com Moser, Musil:

[...] affronta a più riprese l'esperienza che priva l'individuo delle qualità in virtù delle quali può erigersi nella funzione di soggetto: razionalità, autonomia, responsabilità, stabilità [...] La perdita dei suoi attributi di uomo liberale si intensifica fino al loro annullamento: l'individuo [è] di colpo ridotto al suo compito elementare: proteggere la stirpe (MOSER, 1985 apud KRYSINSKI, 1988, p. 34).

Para o professor polonês Wladimir Krysinski, essa fórmula pode definir perfeitamente o universo da dissolução do Eu de Pirandello, pois, em toda sua obra, são encontrados discursos e temáticas que correspondem à perda daquilo que Musil chama "função do eu" e "conceito de eu". Nesse sentido, a poética pirandelliana multiplica as perspectivas, sem que nenhuma seja a verdadeira ou a central, aproximando-se do que assegurava Nietzsche:
O mundo é cognoscível; mas este é interpretável de modos diversos, e não existe nele um sentido, mas inumeráveis sentidos. "Perspectivismo". São os nossos desejos que interpretam o mundo: os nossos instintos com seus prós e contras (1996, p. 16-17).

Não seria equivocado afirmar que o perspectivismo de Nietzsche aproxima-se ao de Pirandello, tão bem exemplificado em Um, nenhum e cem mil, romance em que um determinado sujeito se choca com a própria imagem refletida no espelho, que também impacta com os tantos outros conceitos a ele atribuídos pelos outros. A questão não se resume a "quem era Vitangelo Moscarda?", mas quem era Moscarda para a esposa?, quem era Moscarda para os amigos?, quem era Moscarda para os concidadãos de Richieri?, quem era Vitangelo Moscarda para ele mesmo?

No prefácio da edição de 2010 do romance, Alfredo Bosi questiona: "qual é a lógica interna dessa ficção que timbrou em desfazer toda rede comunicativa entre sujeitos que coabitam o mesmo espaço social?" (2010, p. 14). A resposta está na própria indagação: a lógica está na dissolução da falsa ideia da existência de uma realidade única e cognoscível e a crença na impossibilidade de compreensão dos mecanismos que regem a subjetividade humana.

De acordo com Wladimir Krysinski (1988, p. 148), em Um, nenhum e cem mil revelam-se dois aspectos importantes da subjetividade sobre os quais Pirandello se indaga: o princípio da individualidade e o reconhecimento da alteridade. 
Tomando a individualidade como ponto de partida para entendermos a subjetividade, está clara, em Pirandello, sua convicção de que cada caso humano encontra-se atrelado, irredutivelmente, a um Outro. Mesmo considerando que cada indivíduo é único e, na maioria das vezes, incompreensível, o escritor siciliano reconhece que a subjetividade manifesta-se sempre "em relação" a alguém ou alguma coisa. O ser humano possui, inegavelmente, sua história individual. Entretanto, essa individualidade está intrinsecamente ligada ao fluxo geral, à história coletiva de seu tempo, sendo esse um dos maiores pontos de reflexão de Pirandello: o que resta do ser humano se excluídos os aparatos sociais que o delimitam e engessam de acordo com essa ou aquela circunstância?

A subjetividade, afirma Krysinski, deriva de um senso de singularidade, mas, ao mesmo tempo, tende a repetir sempre os mesmos padrões, oriundos do encontro desestabilizador com o Outro. A individualidade defendida por Pirandello, nesse sentido, contrapõe-se à visão balzaquiana da sociedade entendida como algo decifrável por intermédio da observação de um número finito de tipos humanos e de comportamentos individuais. O ser humano é incompreensível, afirma Pirandello.

Ao tomar consciência de que a vida em sociedade é um engodo, Vitangelo Moscarda opta por uma existência alternativa, livre das imposições sociais, fato que o leva a assumir a condição de louco. Tal escolha assume, no romance, a forma de utopia, pois já que não é possível transformar a sociedade tal como ela está configurada, transforma-se, então, o homem. O sujeito, resoluto a encontrar um sentido e uma essência em si mesmo, só encontra, nesse mergulho, o abismo. A reflexão de Moscarda ou de Mattia sobre a própria existência só faz revelar e reforçar ainda mais o sentimento de obscuridade que envolve a alma humana.

Segundo Krysinski, "il soggetto che riflette sul proprio io si trova sul bordo di um abisso, prova uma vertigine, sconfina nell'insondabile" (1988, p. 153). A insanidade de Vitangelo Moscarda, ao final de Um, nenhum e cem mil, é a exacerbação desse estado reflexivo em que o sujeito descobre que a vida considerada normal é uma ficção, um cômodo fingimento, da qual só se pode escapar pela morte ou pela loucura. A subjetividade de Moscarda, portanto, só é exercida plenamente no manicômio, sua última morada, espaço em que toda tentativa de comunicação com o mundo é extinta.

Serafino Gubbio, o protagonista de Cadernos de Serafino Gubbio operador, é outra personagem de Pirandello que denuncia a impossibilidade de comunicação entre os seres humanos, ao mesmo tempo em que assinala o fim do pleno exercício da subjetividade do homem moderno. Se entendermos o termo subjetividade como a forma segundo a qual o ser humano vê, interpreta e interage com o mundo que o cerca, o operador de câmera Serafino 
Gubbio pode ser considerado um sujeito cuja subjetividade fora absorvida pela máquina. Ele observa, capta as imagens e interpreta a vida através das lentes de sua câmera cinematográfica:

Observo as pessoas nas suas mais banais atividades, para ver se consigo descobrir nos outros aquilo que me falta em todas as coisas que faço: a certeza de que compreendem aquilo que estão fazendo. Num primeiro momento, sim, parece-me que muitos a tenham, pelo modo como se encaram e se cumprimentam, correndo para cá, para lá, atrás dos seus negócios ou de seus caprichos. Mas depois, se paro um pouco para fitá-los dentro dos olhos, com estes meus olhos fixos e silenciosos, eis que logo se escondem. Alguns, aliás, perdem-se numa perplexidade tão inquieta, que se eu continuasse a perscrutá-los, poderiam injuriar-me ou agredir-me. Ora, vamos, fiquem tranquilos. Basta-me isto: saber que não é claro nem certo, nem mesmo para vocês, aquelas mínimas coisas que aos poucos são determinadas pelas normalíssimas condições nas quais vocês vivem. Há um além em tudo. Vocês não querem ou não sabem vê-lo. Assim que, porém, este além brilhe nos olhos de um ocioso como eu que se ponha a observá-los, então vocês se perdem, se perturbam, se irritam. Eu também conheço o dispositivo externo, quero dizer, mecânico da vida que fragorosa e vertiginosamente nos envolve sem tréguas. Hoje, desse ou daquele jeito, isto e aquilo para fazer; correr para cá, com o relógio na mão, para chegar em tempo lá. - Não, meu caro, obrigado: não posso! - Ah, sim, realmente? Sorte sua! Tenho que ir embora... - Às onze, o almoço. - O jornal, a bolsa, o escritório, a escola... - Tempo bom, que pena! Mas os negócios... - Quem está passando? $\mathrm{Ah}$, um carro fúnebre... Um cumprimento, às pressas, a quem se foi. - A oficina, a fábrica, o tribunal... Ninguém tem tempo ou modo de parar um momento para considerar se aquilo que vê os outros fazerem, aquilo que ele mesmo faz, seja realmente o que acima de tudo lhe convém, o que lhe pode dar aquela certeza verdadeira, na qual somente poderia encontrar o repouso. [...] Com uma mão seguramos nossa cabeça, com a outra fazemos um gesto de bêbados. Divirtamo-nos! Sim. Consideramos mais fatigantes e complicadas que o trabalho as diversões que nos são oferecidas; de modo que do repouso nada mais obtemos que um aumento de cansaço. [...] Há uma doença, porém, que não passa. Estão ouvindo? Um vespão que sempre zumbe [...]. O que é? O zumbido dos postes telegráficos? $\mathrm{O}$ arrastar contínuo da roldana ao longo dos fios dos bondes elétricos? O estremecimento premente de tantas máquinas, próximas, distantes? Aquele do motor do automóvel? Aquele do aparelho cinematográfico? A batida do coração não se percebe, não se percebe o pulsar das artérias. Ai de nós se percebêssemos! Mas este zumbido, este tique-taque perpétuo [...] (PIRANDELLO, 1990, p. 17-22).

As primeiras linhas de Cadernos de Serafino Gubbio operador já demonstram a força expressiva dessa obra que desconcerta por não deixar dúvidas de que o homem liberal metafísico está morto, foi triturado pela turbulenta vida moderna e substituiu a realidade natural por outra artificial: vê o mundo através da lente de uma câmera com a intenção de tentar descobrir nos outros aquilo que lhe falta: a certeza de que entendem o que estão fazendo. A forma do romance é um suceder de notas em um diário, que tem o intuito de mostrar o que o protagonista, "um observador de pessoas", captava por intermédio do olhar voraz de sua máquina.

Na época em que Pirandello escreveu esse romance (1914-1915), já havia passado pelos períodos mais turbulentos em relação à crítica e à afirmação de sua obra. Isso significa que já havia su- 
perado a fase inicial, quando pretendia representar subjetivamente o homem moderno, ainda com resquícios de uma narrativa romântica e realista. Em Quaderni di Serafino Gubbio operatore, vemos um Pirandello que submerge na descrição de um mundo onde já não há mais possibilidade de saída na subjetividade e em que a objetividade nos é apresentada em perspectiva.

Comparando o romance de Serafino ao de Mattia Pascal, Carmelo Distante escreve, na introdução da edição de 1990 de Cadernos de Serafino Gubbio operador, que:

[...] se no primeiro era mostrado o quanto era ilusório pensar que se pode fugir de uma triste realidade, gerada por uma sociedade mesquinha e sem ideias, no segundo romance está clara a falência dessa sociedade, sendo que somente no teatro ou no metateatro é que se pode encontrar uma imagem representativa que vá além da ilusão romântica, com o intuito de se tornar cena e denúncia, sem compaixão ou piedade (PIRANDELLO, 1990, p. 6).

Giancarlo Mazzacurati (1995), em um ensaio intitulado Il doppio mondo di Serafino Gubbio, caracteriza o romance de Pirandello como "romanzo delle anamorfosi", ou seja, romance de imagens deformadas, produtos de um enorme aparato "digestivo" (o mercado), que se alimenta de uma realidade natural (os sentimentos, a consciência, os valores, as sensações) e a transforma em mercadoria por intermédio das máquinas vorazes que caracterizam a era moderna.
Forse più che di metamorfosi, occorrerà allora definire i Quaderni di Serafino Gubbio come un romanzo di anamorfosi: perché il meccanismo dominante (l'illusione cinematografica) non produce tanto trasformazione quanto sostituzione della realtà naturale con una realtà artificiale, di secondo grado, che si nutre della prima e la assorbe entro i circuiti totalitari dello spettacolo-merce. La ribellione dell'autentico, congelata in prodotto, può divenire così, per la natura occlusiva e onnivora degli apparati industriali, un fortunato oggetto di consumo. Il mondo pirandelliano delle macchine e delle riproduzioni estetiche meccanizzate, più che trasformare, sostituisce ogni elemento di vita in " cosa " (MAZZACURATI, 1995, p. 251).

A substituição da realidade operada pela máquina é o tema de Cadernos de Serafino Gubbio operador, obra que propõe uma visão derrotada do homem. Serafino Gubbio, cuja maior qualidade é a "impassibilidade diante da ação", é simplesmente uma mão que gira a manivela para que a máquina, essa sim, faça seu trabalho. Ele poderia até se iludir, sonhar que o ritmo como ele movimenta a manivela altera o movimento daqueles atores, mas não ousa fazê-lo, pois tem consciência de ser um "operador que não opera nada". Antes as "coisas" do que o homem, confirma Serafino Gubbio:

Eu perambulava à procura de um modesto alojamento, não tanto para mim, acostumado a passar a noite ao ar livre, amigo dos morcegos e das estrelas, e sim para minha malinha, deixada no depósito da estação (PIRANDELLO, 1990, p. 22).

À medida que a leitura do romance avança, a narrativa descrente de $\mathrm{Pi}$ randello em relação à autonomia e à lucidez do ser humano vai ficando cada vez mais clara. Nas primeiras páginas, 
temos uma personagem que aceitou passivamente o triunfo das máquinas, entregando-se à inevitável constatação de que não passamos de "milhares de minhocas torradas", como diria Mattia Pascal. Em seguida, outra criatura, Simone Pau, entrega-se à loucura de viver uma realidade transfigurada e acredita nela, bem aos moldes do cavaleiro Don Quixote. Na perspectiva desse amigo de Serafino, Simone, o asilo para mendigos onde vivia era um hotel, o fosso bolorento era uma piscina, o tubo enferrujado de onde saía a água para o banho era uma deliciosa ducha. É dessa maneira que ele enxerga a sua realidade.

A adoção dessa perspectiva, mais do que loucura, configura-se como uma possível e única saída para um homem derrotado, uma personagem humorística, em sentido pleno, pois é necessário ver por detrás da aparente comicidade de Simone Pau para perceber sua verdadeira tragédia. Podemos afirmar que Serafino é um escravo de sua máquina filmadora, enquanto Simone Pau é prisioneiro da própria loucura. Ambos têm uma visão particularizada da realidade, cada um a seu modo. Em Il fu Mattia Pascal, a personagem protagonista é soterrada pelas circunstâncias da vida; em Um, nenhum e cem mil, é o olhar do Outro que perturba o pobre Moscarda; no caso de Serafino Gubbio, o sujeito é engolido pela máquina.

Sobre essa forma individualizada de observar o mundo, ao fixar alguns parâmetros interpretativos dos textos modernos, Wladimir Krysinski afirma que a subjetividade é a principal força motora da literatura moderna. Tal assertiva advém da ideia (ou impressão) de que o sujeito tornou-se "observador, juiz, escrivão, avaliador do mundo. [...] quase operador, narrador, auto-narrador e protagonista da narrativa e do discurso" (KRYSINSKI, 2007, p. XXIV). Para o crítico russo, o indivíduo subverteu a ordem estabelecida dos comportamentos coletivos, redefinindo a literatura como força enunciativa individual.

Todavia, o mesmo Krysinski não descarta a possibilidade de questionamentos acerca dessa configuração do sujeito como artífice do próprio discurso e de sua subjetividade:

Será que o sujeito, esta velha categoria da qual ocupa-se a filosofia desde Aristóteles [...] até Heidegger [...] e Sartre [...], este objeto da subjetividade, não foi dissolvido, liquidado, expulso da crítica e da teoria literárias? (2007, p. XXV).

Partindo do questionamento de Krysinski, arriscamos afirmar que, em Pirandello, o sujeito não foi excluído, mas passou a ser visto de outra forma, sempre negativa e autodestrutiva.

Abrindo aqui um parêntese, de acordo com Bruno Pischedda (1997), Walter Benjamin, em A obra de arte na era da reprodutibilidade técnica, de 1936, já percebia o valor de Quaderni di Serafino Gubbio operatore. Como recorda Pischedda, Benjamin havia determinado três elementos distintivos importantes na moderna locação cinematográfica: 
1) a profanação ao desempenho do intérprete, agora submetido aos equipamentos de filmagem; 2) o final da representação unitária, substituída por uma série de trechos remontados; 3) o culto estrelar dos atores promovido pelo mercado cinematográfico (PISCHEDDA, 1997, p. 146, tradução nossa).

Assim, Benjamin já observa que, independente do fato de Pirandello ter representado esses aspectos de maneira inconsciente, o que importa é que ele já havia detectado o problema da reprodução técnica da obra de arte em sua época. Quaderni di Serafino Gubbio operatore é testemunha dessa transformação.

A reprodução da arte no início do século XX, de acordo com Benjamin ([1955?]), atingira um nível tal que não somente se apropriou, copiou, transformou, mas também conquistou seu espaço como procedimento artístico. Todavia, faltava alguma coisa: o aqui e o agora da obra de arte. A reprodutibilidade da obra arrefeceu sua aura, aquilo que a distinguia no universo, pois ao mesmo tempo em que a reprodução liberta o objeto do domínio da tradição, também substitui o "único" pela ocorrência "em massa". O filme é o exemplo mais convincente da liquidação do valor da tradição da herança cultural, como assinala Benjamin, neste trecho em que Pirandello é citado:

Para o cinema, é mais importante que o actor se apresente perante a câmara a si próprio do que perante o público como outrem. Uma das primeiras pessoas a sentir tal mudança do actor, devido à pressão dos testes, foi Pirandello. As observações que faz no seu romance "Filma-se" ${ }^{2}$ continuam válidas apesar de ele se limitar a realçar o lado negativo da questão, e de se referir apenas ao cinema mudo. Porque o cinema sonoro pouco alterou esta questão. $\mathrm{O}$ importante é que se representa para um equipamento e, no caso do filme sonoro, para dois. $\mathrm{O}$ actor de cinema, escreve Pirandello, sente-se no exílio. Exilado não só do palco, mas também da sua própria pessoa: com um mal-estar sombrio sente o inexplicável vazio causado pelo facto de seu corpo se tomar numa manifestação ausente, de se desvanecer e de ser privado da sua realidade, da sua vida, da sua voz e dos sons que emite quando se move, para se transformar numa imagem muda que estremece na tela por um instante para depois desaparecer no silêncio... O pequeno equipamento que representará para o público com a sua sombra, e o actor tem que se contentar com a representação perante a máquina ([1955?], não paginado).

No teatro, não existe um equipamento que promova a mediação entre ator e espectador, o desempenho do artista é apresentado por ele mesmo e pode ser alterado de acordo com a receptividade de quem assiste. No caso do cinema, essa relação é impossível, e a interferência da câmera acarreta duas modalidades de consequências: 1) a representação é submetida a testes óticos; 2) a ausência do público impede que o ator adapte sua atuação, sinta o efeito provocado no espectador. Daí a expressão "ator exilado", cunhada por Pirandello para o ator cinematográfico. $\mathrm{O}$ equipamento toma o lugar do público ao mesmo tempo em que isola o ator, transformando-o em mais um artefato do processo, simplesmente.

Segundo Benjamin, para a obra de arte que surge na era da reprodutibilidade técnica, não há maior contraste que 0 teatro, o palco. Segundo o crítico alemão, 
muitos observadores especializados reconhecem que, no cinema, melhores são os resultados quando menos se representa, já que o ator é visto como um acessório em meio a todo o aparato que o cerca. "Ele é o resultado de várias intervenções”, assevera Benjamin ([1955?], não paginado).

Desse modo, arriscamos dizer que não só a obra de arte perdeu sua aura na era da reprodutibilidade técnica, mas também o ator como sujeito integrante do processo. No caso de Pirandello, o mecanismo que se configura como a perda da aura se manifesta por intermédio de um discurso sobre a subjetividade do homem moderno, que gravita em torno da ideia de um Eu contraditório, incerto e fragmentado.

Voltando a Quaderni di Serafino Gubbio operatori, da mesma forma que o ator de cinema relaciona-se com o público por meio da câmera, é por intermédio dela que Serafino se comunica com o mundo. Em outros termos, a crise do homem moderno dependente das máquinas assolou o teatro em função do cinema e transfigurou, no mesmo fluxo, as relações interpessoais. "E quando as máquinas tomarem conta"? Perguntava-se Mattia Pascal. "O senhor é mesmo necessário?", perguntavam a Serafino Gubbio. Essas são questões fundamentais na obra de Pirandello que colocam em xeque a supremacia do homem, sua arrogância, sua independência e seu orgulho.

A substituição da realidade pela ilusão cinematográfica, a anamorfosi, resume e esclarece a questão central de
Quaderni di Serafino Gubbio operatore. A realidade não é transformada pela máquina, mas passa a ser vista de outra forma, assim como as relações interpessoais sofrem influência direta de fatores exteriores ao sujeito. Um exemplo pertinente é a comparação entre o automóvel e a carruagem, passagem que inicia $o$ terceiro caderno do romance:

Um leve giro. Há uma pequena carruagem que está correndo em frente. - Pó, pópóoo, póoo. O quê? A buzina do automóvel a está puxando para trás? É sim! Parece mesmo, pois, que a faça ir para trás, comicamente. As três senhoras do automóvel riem, viram-se, levantam os braços e cumprimentam com muita vivacidade, entre um confuso e um alegre esvoaçar de véus multicoloridos; e a pobre carruagem envolvida numa nuvem árida, nauseante, de fumo e pó, por mais que o cavalinho fatigado se esforce em puxá-la com o seu trotear estafado, continua a ir para trás, para trás [...] até que desaparece no fim de uma longa avenida fora de mão. Desaparece? Não: que nada! Desapareceu o automóvel. A pequenina carruagem aqui está. [...] Na pequenina carruagem fico eu. [...] Mas o que vocês viram? Uma carruagem ir para trás, como se fosse puxada por um fio, e toda a avenida disparar à frente, num deslizamento longo, confuso, violento, vertiginoso. Eu, ao contrário, eis tudo, posso consolar-me com a lentidão admirando um por um [...] estes grandes plátanos verdes na avenida (PIRANDELLO, 1990, p. 56-57).

Há duas formas evidentes de ver a mesma cena nessa passagem: uma proveniente do olhar das senhoras do automóvel, atrizes da Kosmograph, empresa cinematográfica onde Serafino trabalha; outra do operador que está na carroça. $\mathrm{O}$ interessante nesse jogo de perspectivas é que a máquina, o automóvel, parece subjugar a relação espaço e tempo, pois, 
na verdade, a carroça também segue em frente, mas em uma velocidade tão inferior que parece estar andando para trás. A noção do real, portanto, é alterada de acordo com a posição de quem observa e como observa, fato que se assemelha às novas formas de ver o mundo com o auxílio (ou estorvo) das máquinas. $\mathrm{O}$ contraste entre a modernidade veloz e o que restou da alma romântica do passado de Serafino, envolvido, no momento, pelo mundo das máquinas, mostra-se na calma observação dos verdes plátanos da avenida. A nostalgia manifesta nessa passagem nos remete ao Pirandello que viveu no limiar entre dois mundos, duas realidades, a passagem de um século a outro, sendo que a velocidade do automóvel, assim como toda a vertiginosa pressa do mundo moderno, deformou o olhar.

O dispositivo central do romance é a consciência assustada de que se vive em um mundo caótico, governado por máquinas famintas. O que restou do homem e sua subjetividade, então? Como o ser humano interage com o Outro, na visão de Luigi Pirandello? Essas são duas das tantas questões que perpassam obras como O falecido Mattia Pascal, Um, nenhum e cem mil e Cadernos de Serafino Gubbio operador. No primeiro caso, o Outro é uma ameaça; no segundo, desestabilizador e desconcertante; no terceiro romance, o Outro é algo distante, que só pode ser contemplado através de uma lente. O que há em comum nesses romances é a anulação progressiva da alteridade e a certeza de que o Outro não é mais um espelho no qual o sujeito se reconhece, mas sua negação. A coexistência entre os sujeitos, nesse sentido, é sempre atravessada pela tensão Eu versus Outro, em que um dos indivíduos será sempre escravizado ou simplesmente desconsiderado, não havendo possibilidade de diálogo ou de convivência harmoniosa. Relacionar-se, para Pirandello, sempre foi um problema indissolúvel e um mal necessário.

Talvez a postura sempre negativa em relação ao ser humano advenha de sua própria experiência de vida: um jovem rico que vê a fortuna da família ruir sem que nada pudesse ser feito. Com o alagamento da mina de enxofre do pai, em 1903, Pirandello se dá conta da impotência do homem frente às adversidades da vida e da efemeridade das coisas e das relações. Nada é perpétuo além da certeza de que inventamos realidades incessantemente, com a vã ilusão de que pareçam reais. Em sua obra, Pirandello ressalta com extrema lucidez a condição desesperada do homem que, perdida a fé nos valores objetivos positivistas, perdeu também qualquer possibilidade de encontrar uma verdade absoluta. Dessa forma, tanto o critério da objetividade quanto o da subjetividade entram em crise: de um lado, com a queda da ilusão positivista, a noção de verdade não existe mais; de outro, a verdade não pode estar embasada na subjetividade, pois o sujeito não é mais visto como unidade, mas como contradição, cisão e decadência. As personagens de Pirandello, portanto, são a representação dessa ruína. 


\section{Italian Verism and the subjectivity: the reverse in Luigi Pirandello}

\begin{abstract}
The Italian Verism was an artistic movement that had its inspiration in Émile Zola. In the end of the XIX century and the beginning of the XX such movement was characterized by the belief on the possibility that literature could objectively represent the real. This article aims at reflecting about how the Sicilian writer, playwright and Verism descendant, Luigi Pirandello, approached the subjectivity in some of his works. In order to reach such purpose we elected as object for analysis the novels $O$ falecido Mattia Pascal, Um, nenhum e cem mil and Cadernos de Serafino Gubbio operador. In these works, Pirandello subverts the objectivity suggested by the Verists and raises doubts about the possibility of the subject carrying out his subjectivity in a complete way. According to Pirandello, the subjectivity is a complex mechanism modified by the society, by the modern machines and by the sight of the other.
\end{abstract}

Keywords: Verism. Pirandello. Subjectivity.

\section{Notas}

1 Segundo o físico teórico alemão Werner Heisenberg (1901-1976), mesmo que possa parecer não crível, é preciso acentuar que não devemos pensar a ciência como pronta e acabada, mas a marca da verdadeira ciência, da ciência dos nossos dias, é a incerteza. Tal constatação adveio dos experimentos com partículas realizados por ele, com base nos quais o físico concluiu ser impossível medir com precisão a posição e a velocidade desses elementos.

2 Filma-se foi a tradução para Si gira, o primeiro nome de Quaderni di Serafino Gubbio operatore.

\section{Referências}

ANDRADE, Ana Paula Freitas de. Os $M a-$ lavoglia: o narrador e sua criação. 2006. 115 f. Tese (Doutorado em Teoria Literária) Universidade de São Paulo, São Paulo, 2006.

BAUDELAIRE, Charles. O pintor da vida moderna. In: COELHO, T. (Org.). A modernidade de Baudelaire. Trad. Suely Cassal. Rio de Janeiro: Paz e Terra, 1988. p. 59-158.

BENJAMIN, Walter. A obra de arte na era de sua reprodutibilidade técnica. [1955?]. Disponível em: <http://www.ufrgs.br/obec/ assets/acervo/arquivo/benjamin_reprodutibilidade_tecnica.pdf $>$. Acesso em: 13 jul. 2016.

BERMAN, Marshall. Tudo que é sólido desmancha no ar: a aventura da modernidade. Trad. Carlos Felipe Moiés e Ana Maria L. Ioriatti. São Paulo: Companhia das Letras, 1986.

BOSI, Alfredo. Céu, inferno: ensaios de crítica literária e ideológica. São Paulo: Ática, 2003.

Prefácio. In: PIRANDELLO, Luigi. Um, nenhum e cem mil. Trad. Maurício Santana Dias. São Paulo: Cosac Naify, 2010. p. 14.

DEBENEDETTI, Giacomo. Saggi critici. Seconda serie. Venezia: Marsilio, 1990.

DISTANTE, Carmelo. Introdução. In: PIRANDELLO, Luigi. Cadernos de Serafino Gubbio operador. Trad. Sergio Mauro. Rio de Janeiro: Vozes, 1990. p. 6.

DOSTOIÉVSKI, Fiódor. Notas do subsolo. Trad. Maria Aparecida Soares. São Paulo: L\&PM Pocket, 2008.

HAUSER, Arnold. Historia social de la literatura y el arte: naturalismo e impressionismo 
bajo el signo del cine. Madri: Guadarrama, 1969. v. III.

HEISENBERG, Werner. A imagem da natureza na física moderna. Lisboa: Editora do Brasil, 1980.

KRYSINSKI, Wladimir. Dialéticas da transgressão. Trad. Ignacio Antonio Meis, Michel Peterson e Ricardo Iuri Canko. São Paulo: Perspectiva, 2007.

. Il paradigma inquieto: Pirandello e lo spazio comparativo della modernità. Napoli: Scientifiche Italiane, 1988.

LIMA, João Carlos Felix de. Cultura, imaginação literária e resistência em Alfredo Bosi. Tese (Doutorado em Teoria Literária) - Departamento de Teoria Literária, Universidade de Brasília, Brasília, 2012.

MAZZACURATI, Giancarlo. Pirandello nel romanzo europeu. Bologna: Il Mulino, 1995.

NIETZSCHE, Friedrich. Fragmentos póstumos (1855 / 1886). Campinas: Unicamp, 1996. (Textos Didáticos, n. 22).

NOBILI, Claudia Sebastiana. Pirandello: guida al fu Mattia Pascal. Roma: Carocci, 2004.

PIRANDELLO, Luigi. O falecido Mattia Pascal: seis personagens à procura de um autor. Trad. Mário da Silva, Brutus Pedreira e Elvira Rina. São Paulo: Abril Cultural, 1981. Disponível em: <http://www.ufrgs.br/obec/ assets/acervo/arquivo/benjamin_reprodutibilidade_tecnica.pdf $>$. Acesso em: 13 jul. 2016.

Cadernos de Serafino Gubbio operador. Trad. Sergio Mauro. Rio de Janeiro: Vozes, 1990.

O falecido Mattia Pascal. Trad. Mário da Silva. Rio de Janeiro: Abril Cultural, 1972.

Um, nenhum e cem mil. Trad. Maurício Santana Dias. São Paulo: Cosac Naify, 2010.

PISCHEDDA, Bruno. Conoscere $i$ romanzi di Pirandello. Milano: Rusconi, 1997.
VERGA, Giovanni. Os Malavoglia. Trad. Aurora Fornoni Bernardini e Homero Freitas de Andrade. São Paulo: Abril, 2010.

WILLIAMS, Raymond. Tragédia moderna. Trad. Betina Bichof. São Paulo: Cosac Naify, 2002.

ZOLA, Émile. O romance experimental e o naturalismo no teatro. São Paulo: Perspectiva, 1982. 